\title{
Diabetes should not dissuade arteriovenous fistula formation
}

\author{
ANDREW C GORDON, SHAM DHOLAKIA, DAMIEN ASHBY, JEREMY S CRANE
}

\begin{abstract}
Background: Fistula maturation is a complex multifactorial process with the effect of diabetes on vessel augmentation during fistula formation remaining unclear. Variation in results has reflected in a range of clinical practice with regard to patient selection and fistula formation and so requires more study. The aim of our study was to compare outcomes of diabetic and non-diabetic patients undergoing formation of a new upper limb arteriovenous fistula (AVF) to assess whether diabetes has a prognostic effect on outcome.

Methods: A retrospective cohort study analysing 339 patients looking at both radiocephalic and brachiocephalic fistula formation in diabetic and non-diabetic patients was designed, with the primary outcome being fistula failure and then time taken to mature.

Results: No difference was found between diabetic and nondiabetic patients in terms of fistula failure or time to mature. Conclusions: With AVF remaining the best access for dialysis, diabetic patients should not be discouraged from being offered AVF formation as they have equivalent outcomes to non-diabetic patients.

Br J Diabetes 2016;16:119-122
\end{abstract}

Key words: diabetes, arteriovenous, fistula formation, dialysis

\section{Background}

Diabetes is a leading cause of kidney failure and has an increasing prevalence globally. ${ }^{1}$ Within the UK about 20,000 people with diabetes die prematurely, and renal disease accounts for $11 \%$ and $21 \%$ of deaths in people with type 1 and type 2 diabetes, respectively. ${ }^{2}$ Diabetic patients with end-stage renal failure requiring renal replacement therapy in the form of haemodialysis are best managed with an autologous arteriovenous fistula (AVF), which is regarded as the optimum form of vascular access. ${ }^{3,4}$ Establishing a functioning AVF can be challenging, with up to half of newlyformed fistulas failing to mature adequately to support dialysis

West London Renal and Transplant Centre, Imperial College Healthcare NHS Trust, London, UK

Address for correspondence: Dr Andrew C Gordon West London Renal and Transplant Centre, Imperial College Healthcare NHS Trust, 4th Floor, Hammersmith House, Hammersmith Hospital, London, W12 OSH, UK

E-mail: andrewg2910@googlemail.com

http://dx.doi.org/10.15277/bjd.2016.077 therapy. This is because fistula maturation remains a complex and multifactorial process, with vascular remodelling of both artery and vein being affected by many factors. ${ }^{5-7}$

Diabetic patients are predisposed to a higher incidence of peripheral vascular disease than people without diabetes, with poorer flow rates and a heavier burden of arterial wall calcification. ${ }^{8} \mathrm{As}$ a result, patients undergoing radiocephalic AVFs have historically fared worse than their non-diabetic counterparts, and this may have been misconceived as a reason to exclude diabetic patients from receiving a potential AVF and to offer them alternative forms of vascular access. Vessel mapping, using ultrasound to assess the suitability of vessels pre-fistula formation, has significantly improved outcomes for fistulas in all patients including those with diabetes, and is now recommended in the National Kidney Foundation Kidney Dialysis Outcome Quality Initiative. ${ }^{9}$ Despite this recommendation, there still remains variation in results which has reflected in variations in practice. 9,10

The main aim of the study was to compare the outcome of diabetic and non-diabetic patients undergoing formation of a new upper limb AVF and to assess whether diabetes has a significant prognostic effect. Within our population cohort, radiocephalic and brachiocephalic fistulas tended to be the standard fistulas created and so have been chosen for assessment.

\section{Methods}

Patients

Data were collected from patients seen in a vascular access clinic for formation of an upper arm AVF over a 3.5-year period from June 2011 to December 2014. Eligible patients had diabetes and no previous fistula or other type of vascular access planned. Diabetic patients within the cohort were identified and matched with non-diabetic controls. All patients undergoing brachiocephalic and radiocephalic fistula formation were analysed; eight patients had brachiobasilic fistula formation but were not included as none of these patients had diabetes.

Fistula formation

Suitability of fistula formation was based upon ultrasound scanning of vessels during the clinic appointment where vessel diameter, flow and vessel wall calibre were measured and assessed. A tourniquet was used prior to identifying vessels. Scanning was done by vascular access consultants trained in using ultrasound. Within the fistula formation cohort, the patient study group was identified as those having diabetes and matched with a control non-diabetic group. Groups were matched for other comorbidi- 
ties to reduce confounding factors, which included other risk factors that could affect fistula outcome such as hypertension, hypercholesterolaemia, a previous vascular event (myocardial infarction, transient ischaemic attack and cerebrovascular accident) or use of a statin, antiplatelet agent or other anticoagulant. Demographic data were also collected.

All patients received oral ciprofloxacin and flucloxacillin antibiotic prophylaxis before the procedure as per local microbiology and vascular access guidelines. Precautionary measures used to minimise surgical site infection included the application of Betadine $^{\circledR}$ into the wound during closure and application of an Aquace ${ }^{\circledR}$ and Tegaderm ${ }^{\circledR}$ dressing once the wound had been closed. None of the patients were allergic to penicillin or Betadine $^{\circledR}$.

All AVFs followed a standardised method of formation under local anaesthetic used in each case. The same equipment and materials were used; anastomoses were formed using 6.0 Prolene. All procedures were performed with a consultant surgeon as the primary operator. Surgical loupes were worn for radiocephalic fistula formation.

\section{Outcome measures}

Patients were followed up at weeks 1 and 6 and then at regular intervals over the following 12 months, with interval Doppler ultrasound scans (USS) to assess maturity, flow and anatomy. The primary outcome was to compare the numbers of failed fistulas and identify the proportion of successfully mature fistulas defined as either being used regularly for haemodialysis or, in pre-dialysis patients, criteria defined by the fistula first initiative.

Maturity and failure were divided into primary or secondary, depending on whether a fistula underwent an intervention to aid maturation, which included angioplasty for stenosis or side branch ligation to augment flow. Secondary outcomes included comparison of the overall time taken to reach maturity.
Table 1 Patient demographics at baseline

\begin{tabular}{lll}
\hline & Radiocephalic & Brachiocephalic \\
\hline Mean age (years) & 65.19 & 69.11 \\
\hline Gender (M:F) & $25: 24$ & $112: 110$ \\
$\begin{array}{l}\text { Side of arteriovenous } \\
\text { fistula (left:right) }\end{array}$ & $37: 12$ & $167: 55$ \\
$\begin{array}{l}\text { Ethnicity (Caucasian: } \\
\text { Asian:African) }\end{array}$ & $22: 20: 7$ & $99: 120: 3$ \\
\hline
\end{tabular}

\section{Statistical analysis}

IBM SPSS Statistics 22.0 was used for statistical analysis. Fisher's exact test and Mann-Whitney $U$ tests were used for non-parametric data; $p<0.05$ was considered statistically significant.

\section{Results}

\section{Patients}

Of the 281 eligible patients undergoing brachiocephalic fistula formation, 222 patients were analysed (115 diabetic patients and 107 non-diabetic patients) and 59 patients were omitted due to incomplete data (Table 1). Of the 58 eligible patients undergoing radiocephalic formation, 49 patients were analysed (25 diabetic patients and 24 non-diabetic patients) and 9 patients were omitted due to incomplete data.

\section{Fistula outcomes}

Figure 1a shows the overall proportions of maturity and failure in all patients undergoing radiocephalic AVF formation; 59\% (29 patients) having this procedure went on to successful primary maturity with a further $14 \%$ (7 patients) developing a mature

Figure 1. Arteriovenous fistula outcomes

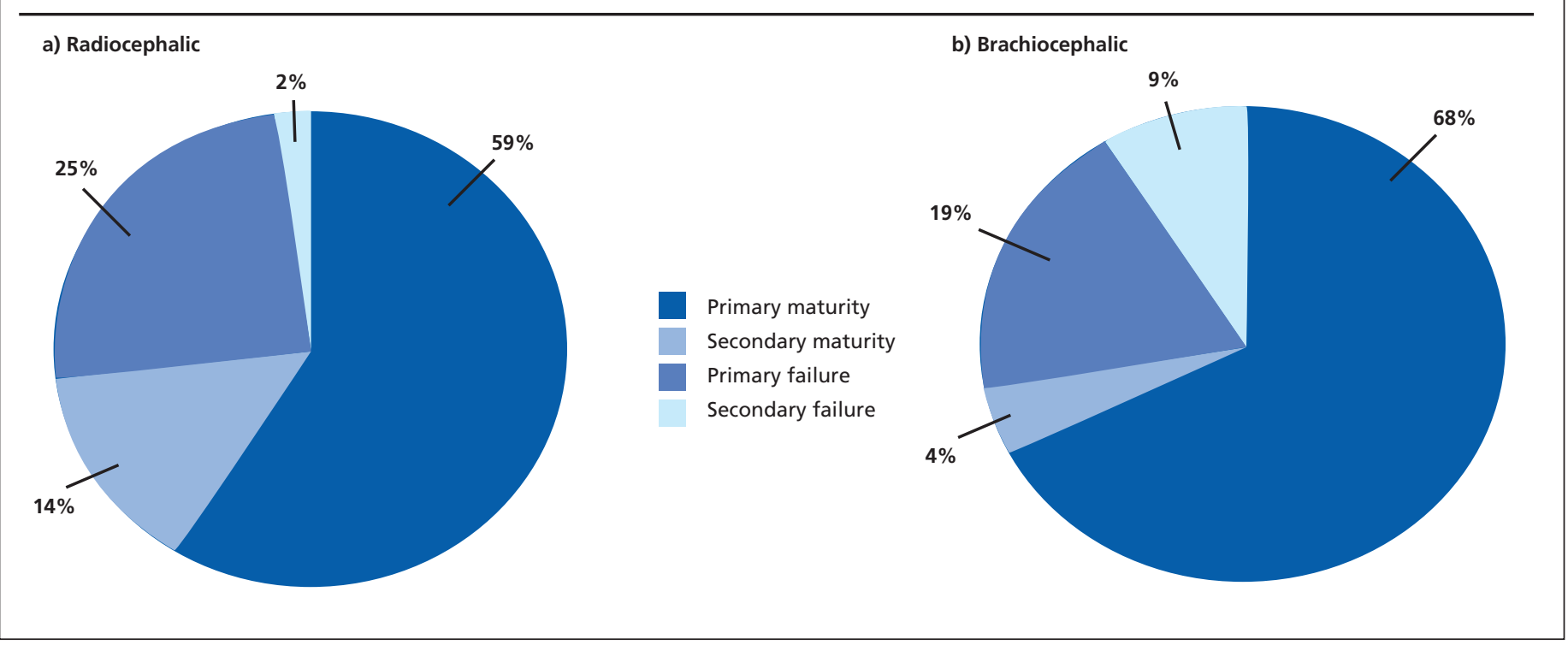


Figure 2. Time to maturity for arteriovenous fistulas in patients with and without diabetes

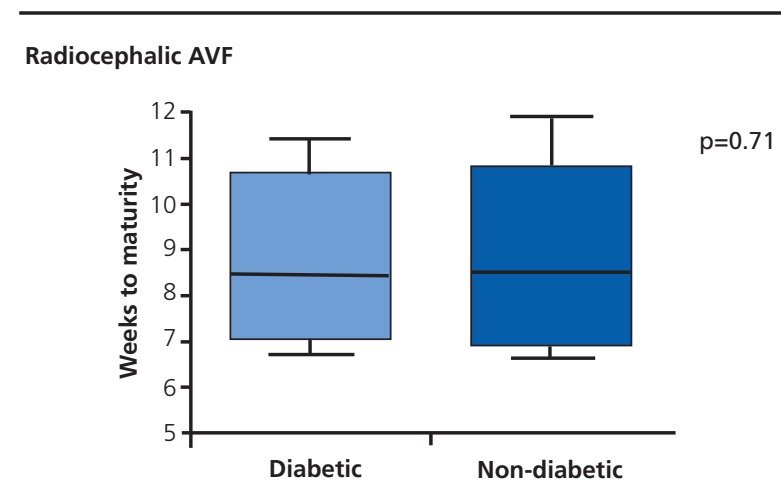

Brachiocephalic AVF

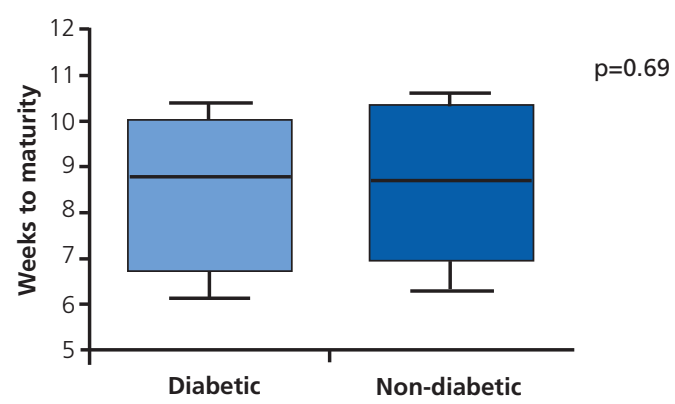

working fistula after intervention. The overall failure for radiocephalic AVF was 27\% (13 patients). There was no significant difference between patients with or without diabetes $(p=0.84)$. The median time to maturity in patients with diabetes was 8.50 weeks (range 6.7-11.4) compared with 8.51 weeks (range 6.611.9) in non-diabetic patients (Figure 2). Again, there was no significant difference between patients with or without diabetes $(p=0.71)$.

For patients undergoing brachiocephalic AVF formation (Figure 1b), 68\% (151 patients) went on to successful primary maturity with a further 4\% (10 patients) developing a mature working fistula after intervention. The overall failure rate for brachiocephalic AVF was 27\% (61 patients). No significant differences for maturity rate $(p=0.86)$ or primary failure rate $(p=0.93)$ were seen between diabetic and non-diabetic patients undergoing brachiocephalic AVF. The median time to maturity was 8.8 weeks (range 6.1-10.4) in diabetes patients and 8.7 weeks (range 6.3-10.5) in patients without diabetes ( $p=0.69$ for diabetes vs. no diabetes).

\section{Discussion}

This study adds to the growing body of evidence that diabetes should not be a factor dissuading health professionals to recommend patients who have diabetes to have a fistula formation to support them while having haemodialysis. ${ }^{10}$ Our results support evidence that there is no significant difference in patients who have diabetes undergoing fistula formation compared with those who do not in terms of successful outcome or complications. Both primary and secondary outcomes showed no statistically significant difference in either brachiocephalic or radiocephalic AVF formation. We acknowledge that other types of fistula can be formed, which we can hypothesise would also have similar results between diabetic and non-diabetic patients, based on our results. However, within our cohort these were the most common types of fistulas formed.

Diabetes mellitus has long been thought to negatively affect the longevity and success of native AVFs, with some evidence suggesting higher rates of early fistula failure in people with diabetes. Several other studies highlight diabetes - along with increasing age, female gender and AVF surveillance - as the main predictors of outcome. ${ }^{11}$ The perceived increase in risk of fistula failure attributed to diabetes arises from the extensive atherosclerotic disease and calcification presenting in the arteries of these patients. It is postulated that impaired flow due to diabetes inhibits physiological dilation of the artery following an arteriovenous anastomosis creation, which in turn impedes venous dilation and maturation. Tight glycaemic control is encouraged as poor control exacerbating severity of disease is thought to affect outcome. ${ }^{12,13}$ However, our results support the literature to show that, with careful assessment using vessel mapping and optimisation of diabetic control, these patients can have similar outcomes with a successful working fistula to non-diabetic dialysis patients and so should not be excluded from this optimum form of vascular access. ${ }^{14}$ In an 8-year analysis of complications in AVFs, no increase in complication rates was seen due to diabetes. ${ }^{15,16}$ There has also been published work suggesting that vein diameter (and not diabetes) was a major significant independent predictor of maturation, which makes vessel mapping such a key point in patient pre-assessment. ${ }^{17}$

Surgical experience is also thought to play an important role in the success of an AVF, with a 34\% lower primary failure rate reported in fistulas created by experienced surgeons. ${ }^{18,19}$ There is evidence suggesting an increased failure in smaller radiocephalic fistulas, or cases with increased steal syndrome, which were attributed to microvascular damage associated with diabetes; these may not be relevant due to the numerous confounding factors associated with this population. ${ }^{20,21}$

Our small sample size is a limitation of our study and conclusions based on these results are limited. However, the conclusions drawn from the results support and add to existing evidence. As this was a retrospective analysis of our cohort, we were unable to actively recruit further patients to increase the size of the groups. This, combined with the ethnic variation we have seen of patients within our area, may make it difficult to generalise the conclusions to the entire population. Although we made an effort to match populations, we cannot be certain all confounding factors were eliminated. However, the patients reported in our study should be representative of the general renal failure population.

\section{Conclusions}

This study supports the growing body of evidence which sug- 


\section{Key messages}

- The presence of diabetes has been cited as a reason for avoiding the formation of arteriovenous fistulas (AVFs)

- The proportions of successful brachiocephalic or radiocephalic AVFs did not differ between patients with or without a diagnosis of diabetes in a retrospective study in patients with end-stage renal disease

- Diabetes should not be a factor in determining the suitability of dialysis patients for an autologous AVF

gests that creating an AVF in diabetic patients should not be discouraged and that diabetes is not a prognostic factor regarding outcome. Although there are recognised vascular complications with diabetes, the relationship of these to fistula success remains uncertain and, certainly, diabetes should not be a factor in turning dialysis patients away from an autologous AVF.

Conflict of interest We declare no conflicts of interest. AG and SD collected data and analysed the results with AG writing the first draft of the manuscript, all authors contributed equally to the manuscript with JC supervising as the responsible consultant.

\section{Funding None}

\section{References}

1. Shaw JE, Sicree RA, Zimmet PZ. Global estimates of the prevalence of diabetes for 2010 and 2030. Diabetes Res Clin Pract 2010;87:4-14. http://dx.doi.org/10.1016/j.diabres.2009.10.007

2. Diabetes UK. State of the Nation 2014. Available at: https://www.diabetes.org.uk/About_us/What-we-say/Statistics/State-of-the-nation-challenges-for-2015-and-beyond

3. NKF-DOQI clinical practice guidelines for vascular access. VIII. Timing of access placement. Am J Kidney Dis 1997;30(Suppl 3):S160.

4. Fluck R, Kumwenda M. UK Renal Association Clinical Practice Guidelines 5th Edition 2008-2011, page 3, Vascular access for haemodialysis.

5. Dixon BS. Why don't fistulas mature? Kidney Int 2006;70:1413-22. http://dx.doi.org/10.1038/sj.ki.5001747

6. Asif A, Roy-Chaudhary P, Beathard G. Early arteriovenous fistula failure: a logical proposal for when and how to intervene. Clin J Am Soc Nephrol 2006;1:332-9. http://dx.doi.org/10.2215/CJN.00850805

7. Roy-Chaudhury P, Spergel LM, Besarab A, Asif A, Ravan P. Biology of arteriovenous fistula failure. J Nephrol 2007;20:150-63.

8. Malovrh M. Native arteriovenous fistula: preoperative evaluation. Am J Kidney Dis 2002;39:1218-25.

http://dx.doi.org/10.1053/ajkd.2002.33394

9. Sidawy AN, Spergel LM, Besarab A, et al. The Society for Vascular Surgery: clinical practice guidelines for the surgical placement and maintenance of arteriovenous haemodialysis access. J Vasc Surg 2008;48(5 Suppl):S20-5. http://dx.doi.org/10.1016/j.jvs.2008.08.042

10. Sedlacek M, Teodoresku V, Falk A, Vassalotti JA, Uribarri J. Hemodialysis access placement with preoperative vascular mapping: comparison between patients with and without diabetes. Am J Kidney Dis 2001; 38:560-4. http://dx.doi.org/10.1053/ajkd.2001.26873

11. Murphy GJ, Nicholson ML. Autogeneous elbow fistulas: the effect of diabetes mellitus on maturation, patency, and complication rates. Eur J Vasc Endovasc Surg 2002;23:452-7.

http://dx.doi.org/10.1053/ejvs.2002.1613

12. Lin SL, Huang CH, Chen HS, Hsu WA, Yen CJ, Yen TS. Effects of age and diabetes on blood flow rate and primary outcome of newly created hemodialysis arteriovenous fistulas. Am J Nephrol 1998;18:96-100. http://dx.doi.org/10.1159/000013315

13. Allon M, Ornt DB, Schwab SJ, et al. Factors associated with the prevalence of AV fistulas in hemodialysis patients in the HEMO study. Kidney Int 2000;58:2178-85. http://dx.doi.org/10.1111/j.1523-1755.2000.00391.x

14. National Kidney Foundation. I. Clinical Practice Guidelines and Clinical Practice Recommendations 2006 Updates; I. Clinical Practice Guidelines for Vascular Access. Available at: https://www.kidney.org/sites/ default/files/docs/12-50-0210_jag_dcp_guidelines-hd_oct06_sectiona_ ofc.pdf

15. Afsar B, Elsurer R. The primary arteriovenous fistula failure - a comparison between diabetic and non-diabetic patients: glycemic control matters. Int Urol Nephrol 2012;44:575-81. http://dx.doi.org/10.1007/s11255-011-9978-x

16. Fokou M, Teyang A, Ashuntantang G, et al. Complications of arteriovenous fistula for hemodialysis: an 8-year study. Ann Vasc Surg 2012;26:680-4. http://dx.doi.org/10.1016/j.avsg.2011.09.014

17. Lauvao LS, Ihnat DM, Goshima KR, Chavez L, Gruessner AC, Mills JL Sr. Vein diameter is the major predictor of fistula maturation. J Vasc Surg 2009;49:1499-504. http://dx.doi.org/10.1016/j.jvs.2009.02.018

18. Saran R, Elder SJ, Goodkin DA, et al. Enhanced training in vascular access creation predicts arteriovenous fistula placement and patency in hemodialysis patients: results from the dialysis outcomes and practice patterns study. Ann Surg 2008;247:885-91. http://dx.doi.org/10.1097/SLA.0b013e31816c4044

19. Goodkin DA, Pisoni RL, Locatelli F, Port FK, Saran R. Hemodialysis vascular access training and practices are key to improved access outcomes. Am J Kidney Dis 2010;56:1032-42. http://dx.doi.org/10.1053/j.ajkd.2010.08.010

20. Konner K. Primary vascular access in diabetic patients: an audit. Nephrol Dial Transplant 2000;15:1317-25. http://dx.doi.org/10.1093/ndt/15.9.1317

21. Ernandez T, Saudan P, Berney T, Merminod T, Bednarkiewicz M, Martin PY. Risk factors for early failure of native arteriovenous fistulas. Nephron Clin Pract 2005;101:39-44. http://dx.doi.org/10.1159/000085710 